\title{
Model-Based Fuzzy Modeling and Control for Autonomous Underwater Vehicles in the Horizontal Plane
}

Wen-Jer Chang

Proferrors, Department of Marine Engineering, National Taiwan Ocean University, Keelung, Taiwan 202, R.O.C., wjchang@mail.ntou.edu.tw

Wei Chang

Student, Department of Marine Engineering, National Taiwan Ocean University, Keelung, Taiwan 202, R.O.C.

Hsien-Hsueh Liu

Student, Department of Marine Engineering, National Taiwan Ocean University, Keelung, Taiwan 202, R.O.C.

Follow this and additional works at: https://jmstt.ntou.edu.tw/journal

Part of the Engineering Commons

\section{Recommended Citation}

Chang, Wen-Jer; Chang, Wei; and Liu, Hsien-Hsueh (2003) "Model-Based Fuzzy Modeling and Control for Autonomous Underwater Vehicles in the Horizontal Plane," Journal of Marine Science and Technology. Vol. 11: Iss. 3, Article 4. DOI: $10.51400 / 2709-6998.2276$

Available at: https://jmstt.ntou.edu.tw/journal/vol11/iss3/4

This Research Article is brought to you for free and open access by Journal of Marine Science and Technology. It has been accepted for inclusion in Journal of Marine Science and Technology by an authorized editor of Journal of Marine Science and Technology. 
Model-Based Fuzzy Modeling and Control for Autonomous Underwater Vehicles in the Horizontal Plane

Acknowledgements

This work was supported by the National Science Council of the Republic of China under Contract NSC912815-C-019-002-E. 


\title{
MODEL-BASED FUZZY MODELING AND CONTROL FOR AUTONOMOUS UNDERWATER VEHICLES IN THE HORIZONTAL PLANE
}

\author{
Wen-Jer Chang*, Wei Chang**, and Hsien-Hsueh Liu**
}

Key words: Takagi-Sugeno fuzzy model, sector nonlinearity, parallel distributed compensation, linear matrix inequality.

\section{ABSTRACT}

In this paper, the modeling and control of nonlinear Autonomous Underwater Vehicle (AUV) system is considered by using a TakagiSugeno $(T-S)$ type fuzzy model. Applying the AUV $T-S$ fuzzy model, one can develop a model-based fuzzy controller design utilizing the concept of Parallel Distributed Compensation (PDC). The main idea of the controller design approach is to derive each control rule so as to compensate each rule of a fuzzy system. The design procedure is conceptually simple and natural. Finally, the responses of states of AUV dynamic real system and AUV dynamic $T-S$ fuzzy model will be shown in the simulation.

\section{INTRODUCTION}

The control of AUV is a field of increasing interest due to its many interesting applications [8]. The AUV may perform environmental surveying; inspect undersea cables and offshore oil installations, and find sunken ships, aircraft and other lost artifacts. As they are undeterred, they may operate under ice, opening up vast, largely unexplored arctic areas that are inaccessible to any other kind of research vessel, and operate at depths too deep for tethered vehicles. One interesting class of AUV available control force in surge and control torques in roll, pitch and yaw, but no actuators in sway and heave. Another interesting thruster configuration is that the AUV has no actuator in roll. In this paper, one considers the kinematics and dynamic equations of motion of the AUV $[1,11]$ in the horizontal plane. It interests as a study case in nonlinear controller design because the model exhibits nonlinear interaction

\footnotetext{
Paper Submitted 05/29/03, Accepted 09/23/03. Author for Correspondence: Wen-Jer Chang.

*Proferrors, Department of Marine Engineering, National Taiwan Ocean University, Keelung, Taiwan 202, R.O.C.

E-mail: wjchang@mail.ntou.edu.tw

**Student, Department of Marine Engineering, National Taiwan Ocean University, Keelung, Taiwan 202, R.O.C.
}

in three degrees of freedom (surge, sway and yaw). The control inputs are the thruster surge force and the thruster yaw torque. This AUV has no side thruster.

In this paper, $T-S$ type fuzzy model is used to describe the nonlinear AUV system. The fuzzy model proposed by Takagi and Sugeno [12] is described by fuzzy IF-THEN rules which represent local linear inputoutput relations of a nonlinear system. Its main feature is used to express the local dynamics of each fuzzy implication by a linear system model. Applying the AUV T-S fuzzy model, one can develop a model-based fuzzy controller design approach utilizing the concept of PDC [2-7, 13-18]. The PDC concept is useful for the fuzzy controller design of $T-S$ type fuzzy models and its main idea of the proposed controller design approach is to derive each control law so as to compensate each rule of a fuzzy system. The design procedure is conceptually simple and natural. Finally, applying Linear Matrix Inequality (LMI) $[6,13,16]$ design technology, one can design a nonlinear fuzzy controller for the AUV system. Hence, the purpose of this paper is to develop a methodology to design a stable fuzzy controller for the nonlinear AUV system via the PDC concept and the LMI method.

The organization of this paper is presented as follows. Section 2 describes the $T-S$ type fuzzy model and the modeling of nonlinear AUV systems. Section 3 will provide the stability conditions for the existence of the $T-S$ fuzzy controllers. The simulated results are described in Section 4. Finally, a conclusion is given in Section 5.

\section{MODELING THE NONLINEAR AUV SYSTEM BY USING $T-S$ FUZZY METHOD}

In this section, we first begin with representing a given nonlinear plant by the so-called $T-S$ fuzzy model [2-7, 13-18]. The fuzzy model proposed by Takagi and Sugeno is described by fuzzy IF-THEN rules which represent local linear input-output relations of a nonlinear system. Next, one will find the kinematics and dynamic equations of motions of the AUV, and use $T-$ 
$S$ type fuzzy model to describe the nonlinear AUV system.

\section{A. Description of $T-S$ Type Fuzzy Model}

The main feature of $T-S$ fuzzy model is to express the local dynamics of each fuzzy implication by a linear system model. To design a fuzzy controller, one needs a $T-S$ fuzzy model for a nonlinear system. Therefore, the construction of a fuzzy model represents an important and basic procedure in this approach. In our approaches for constructing fuzzy model is derived from given nonlinear system equations. Fig. 1 illustrates the model-based fuzzy modeling and controller design procedure. The approach utilizes the idea of "sector nonlinearity", "local approximation", or a combination of them to construct fuzzy models. Sector nonlinearity is based on the following idea. Consider a simple nonlinear system $\dot{x}(t)=f(x(t))$, where $f(0)=0$. The aim is to find a simple nonlinear system $\dot{x}(t)=f(x(t)) \in\left[a_{1}\right.$ $\left.a_{2}\right] x(t)$, where $a_{1}$ and $a_{2}$ are constant scalars.

This approach guarantees an exact fuzzy model construction. However, it is sometimes difficult to find global sectors for general nonlinear systems. In this case, one can consider local sector nonlinearity. This is reasonable as variables of physical systems are always bounded. Fig. 2 and Fig. 3 show the local sector nonlinearity and how to find the $T-S$ fuzzy method (membership functions) through it. From the local sector nonlinearity (Fig. 2) one can define the membership functions through its geometrical structures (Fig. 3).

Consider the following nonlinear system:

$$
f(x)=z(t) \in\left[a_{1} a_{2}\right] x(t)=M_{1}(t) a_{1} x(t)+M_{2}(t) a_{2} x(t)
$$

where, $z(t)$ is known premise variable that may be function of the state variable, external disturbance, and/ or time. $M_{1}(t)$ and $M_{2}(t)$ are fuzzy sets. Fig. 3 describes the geometrical structures of local sector nonlinearity, where two linear equations $a_{1} x(t)$ and $a_{2} x(t)$ help to the linearity to the nonlinear function . It is obvious that $M_{1}$ $(t)$ and $M_{2}(t)$ can be described as follows:

$$
\begin{aligned}
& M_{1}(t)=\frac{z(t)-a_{2} x(t)}{a_{1} x(t)-a_{2} x(t)}, M_{2}(t)=\frac{a_{1} x(t)-z(t)}{a_{1} x(t)-a_{2} x(t)} \\
& M_{1}(t), M_{2}(t) \geq 0, M_{1}(t)+M_{2}(t)=1
\end{aligned}
$$

One can define the membership functions (Fig. 4) from (2). Then, a nonlinear system can be represented by the $T-S$ type fuzzy model dependent on the membership functions. The $i$ th rule of the $T-S$ fuzzy model is of the following form:

$$
\begin{aligned}
& \text { IF } z_{1}(t) \text { is } M_{i 1} \text { and } \ldots \text { and } z_{p}(t) \text { is } M_{i p}, \\
& \text { THEN } \dot{x}(t)=\boldsymbol{A}_{i} x(t)+\boldsymbol{B}_{i} u(t), \quad i=1,2, \ldots, q .
\end{aligned}
$$

were $M_{i p}$ is the fuzzy set and $x(t) \in \boldsymbol{R}^{n}$ is the number of model rules; $u(t) \in \boldsymbol{R}^{m}$ is the state vector, is the input vector and $\boldsymbol{A}_{i} \in \mathbf{R}^{n \times n}, \boldsymbol{B}_{i} \in \mathbf{R}^{n \times m} ; z_{1}(t), \ldots, z_{p}(t)$ are known premise variables that may be functions of the state variables, external disturbances, or time. The $z(t)$ is denoted as the vector containing all the individual elements $z_{1}(t), \ldots, z_{p}(t)$, where $p$ is the premise variable numbers. Given a pair of $(x(t), u(t))$, the final outputs of the fuzzy systems are inferred as follows:

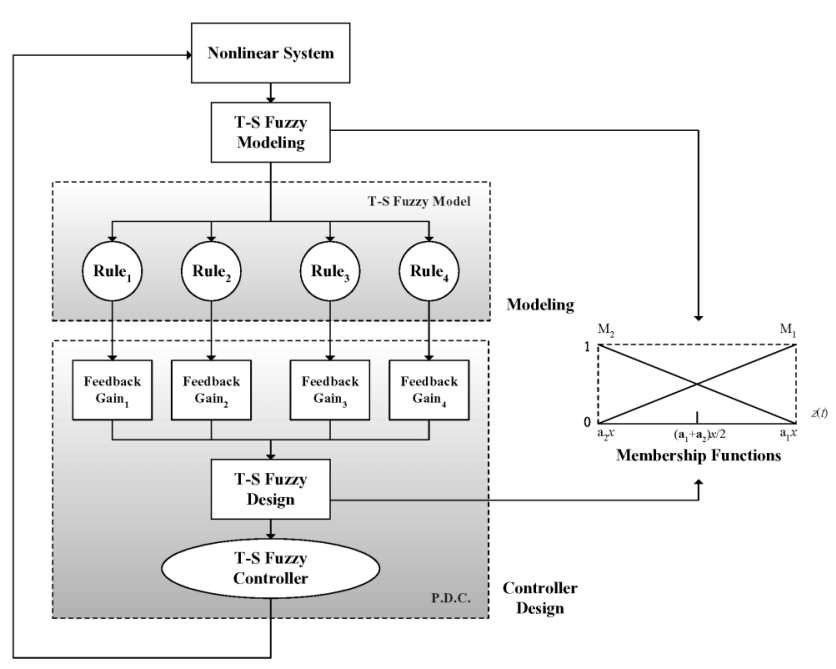

Fig. 1. Model-based fuzzy modeling and controller design.

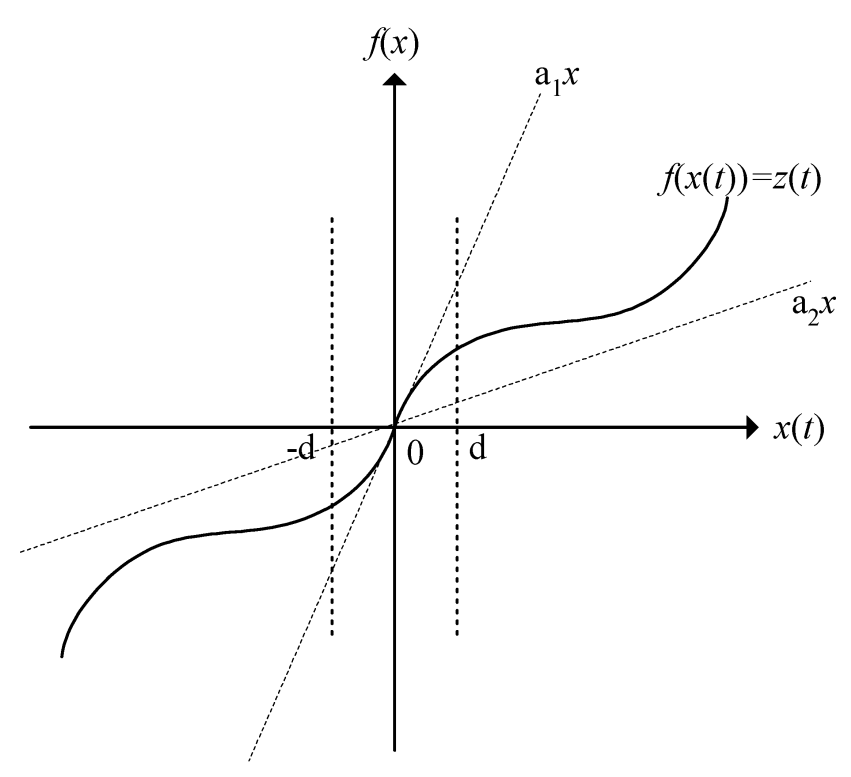

Fig. 2. Local sector nonlinearity. 


$$
\begin{aligned}
\dot{x}(t) & =\frac{\sum_{i=1}^{q} \omega_{i}(z(t))\left\{\boldsymbol{A}_{i} x(t)+\boldsymbol{B}_{i} u(t)\right\}}{\sum_{i=1}^{q} \omega_{i}(z(t))} \\
& =\sum_{i=1}^{q} h_{i}(z(t))\left\{\boldsymbol{A}_{i} x(t)+\boldsymbol{B}_{i} u(t)\right\}
\end{aligned}
$$

where

$$
\begin{aligned}
& z(t)=\left\lfloor z_{1}(t), z_{2}(t), \ldots, z_{p}(t)\right\rfloor \\
& \omega_{i}(z(t))=\prod_{j=1}^{p} M_{i j}\left(z_{j}(t)\right) \\
& h_{i}(z(t))=\frac{\omega_{i}(z(t))}{\sum_{i=1}^{q} \omega_{i}(z(t))}
\end{aligned}
$$

for all $t$. The term $M_{i j}\left(z_{j}(t)\right)$ is the grade of membership of $z_{j}(t)$ in $M_{i j}$. Since

$$
\left\{\begin{array}{l}
\sum_{i=1}^{q} \omega_{i}(z(t))>0 \\
\omega_{i}(z(t)) \geq 0, \quad i=1,2, \ldots, q
\end{array}\right.
$$

on can obtain

$$
\left\{\begin{array}{l}
\sum_{i=1}^{q} h_{i}(z(t))=1 \\
h_{i}(z(t)) \geq 0, \quad i=1,2, \ldots, q
\end{array}\right.
$$

for all $t$. Note that $\omega_{i}(z(t))$ is the weight of the $\mathrm{i}-t h$ rule and it is appropriate for membership values.

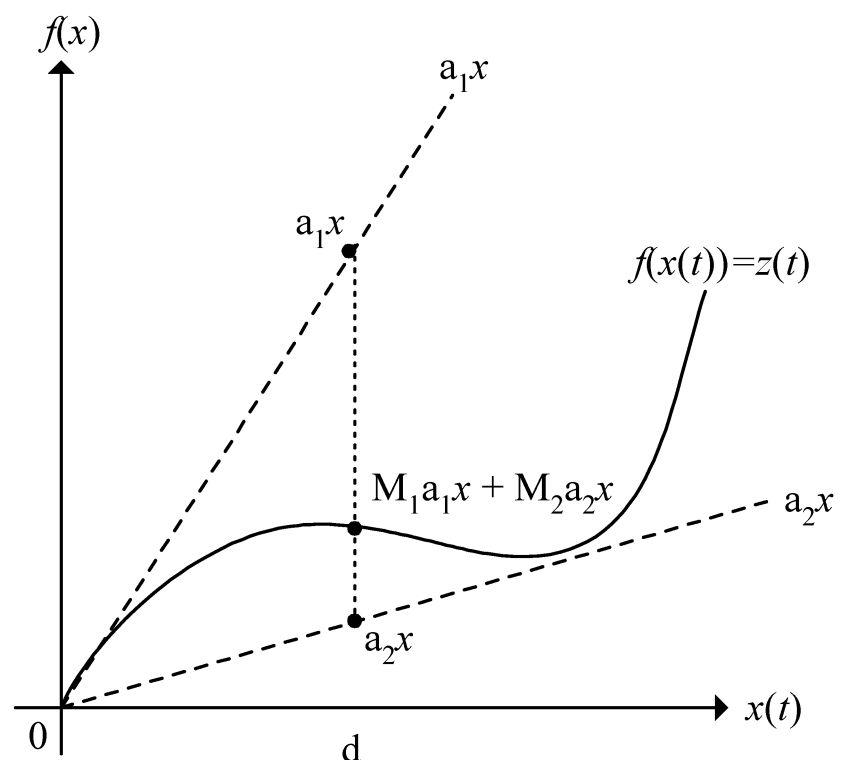

Fig. 3. Geometrical structures.

\section{B. Modeling the Nonlinear AUV System}

In order to simplify the motions of AUV, it is assumed that the AUV active in horizontal plane. From [1], it is known that the model must have the applicable homogeneity properties. So one can obtain the following coordinate transform:

$$
\begin{aligned}
& s_{1}=\cos (\psi) x-\sin (\psi) y \\
& s_{2}=-\sin (\psi) x+\cos (\psi) y \\
& s_{3}=\psi
\end{aligned}
$$

and the AUV state equations are given as follows:

$$
\begin{aligned}
& \dot{s}_{1}=u+s_{2} r \\
& \dot{s}_{2}=v+s_{1} r \\
& \dot{s}_{3}=r \\
& \dot{u}=\frac{m_{22}}{m_{11}} v r-\frac{d_{11}}{m_{11}} u+\frac{1}{m_{11}} \tau_{1} \\
& \dot{u}=\frac{m_{11}}{-m_{22}} u r-\frac{d_{22}}{m_{22}} v \\
& \dot{r}=\frac{m_{11}-m_{22}}{m_{33}} u v-\frac{d_{33}}{m_{33}} r+\frac{1}{m_{33}} \tau_{3}
\end{aligned}
$$

where the notation $s_{1}, s_{2}$ and $s_{3}$ are the transitional coordinate, $u$ (surge speed) and $v$ (sway speed) are the body fixed frame component of the vehicle's velocity, $x$ and $y$ are the Cartesian coordinate of its center of mass, $\psi$ defines its orientation, and $r$ is the vehicle's angular speed. Furthermore, the thruster force in surge and the thruster yaw torque are defined by $\tau_{1}$ and $\tau_{3}$, respectively. Here, the side thruster is not considered, i.e., $\tau_{2}=0$. In addition, $m_{11}, m_{22}, m_{33}$ are the effect of mass and hydrodynamic added mass terms $d_{11}, d_{22}, d_{33}$ are the hydrodynamic damping terms. In order to notation, the states and control inputs are redefined as follows.

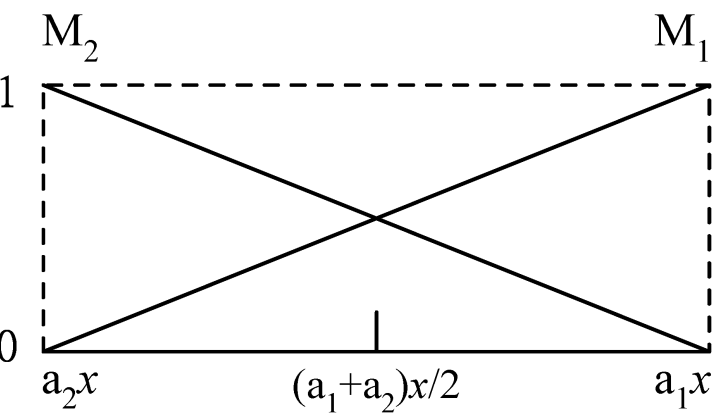

Fig. 4. Membership functions. 
$\boldsymbol{x}(t)=\left[\begin{array}{llllll}x_{1} & x_{2} & x_{3} & x_{4} & x_{5} & x_{6}\end{array}\right]^{T}=\left[\begin{array}{llllll}s_{1} & s_{2} & s_{3} & u & v & r\end{array}\right]^{T}$

$$
\boldsymbol{u}(t)=\left[\begin{array}{ll}
u_{1} & u_{2}
\end{array}\right]^{T}=\left[\begin{array}{ll}
\tau_{1} & \tau_{3}
\end{array}\right]^{T}
$$

For simplicity, it is assumed that the sway speed $x_{5}(t) \in[-0.2,0.2]$ and the vehicle's angular speed $x_{6}(t)$ $\in[-0.2,0.2]$. Of course, one can assume any applicable range for $x_{5}(t)$ and $x_{6}(t)$ to construct fuzzy model. Equations (13-18) can be rewritten as

$$
\begin{aligned}
\dot{\boldsymbol{x}}(t) & =\left[\begin{array}{cccccc}
0 & x_{6} & 0 & 1 & 0 & 0 \\
-x_{6} & 0 & 0 & 0 & 1 & 0 \\
0 & 0 & 0 & 0 & 0 & 1 \\
0 & 0 & 0 & -\frac{d_{11}}{m_{11}} & \frac{m_{22}}{m_{11}} x_{6} & 0 \\
0 & 0 & 0 & -\frac{m_{11}}{m_{22}} x_{6} & -\frac{d_{22}}{m_{22}} & 0 \\
0 & 0 & 0 & \frac{m_{11}-m_{22}}{m_{33}} x_{5} & 0 & -\frac{d_{33}}{m_{33}}
\end{array}\right] \boldsymbol{x}(t) \\
& +\left[\begin{array}{cc}
0 & 0 \\
0 & 0 \\
0 & 0 \\
1 & 0 \\
m_{11} & 0 \\
0 & 0 \\
0 & \frac{1}{m_{33}}
\end{array}\right] \boldsymbol{u}(t)
\end{aligned}
$$

where $\boldsymbol{x}(t)=\left[\begin{array}{llllll}x_{1}(t) & x_{2}(t) & x_{3}(t) & x_{4}(t) & x_{5}(t) & x_{6}(t)\end{array}\right]^{T}, u(t)=$ $\left[\begin{array}{ll}u_{1}(t) & u_{2}(t)\end{array}\right]^{T}$. Note that $x_{5}(t)$ and $x_{6}(t)$ are nonlinear terms. Next, calculate the minimum and maximum values of $x_{5}(t)$ and $x_{6}(t)$ under $x_{5}(t) \in[-0.2,0.2]$ and $x_{6}$ $(t) \in[-0.2,0.2]$. They are obtained as follows:

$$
\begin{aligned}
& \max x_{5}(t)=0.2, \min x_{5}(t)=-0.2, \\
& \max x_{6}(t)=0.2, \min x_{6}(t)=-0.2
\end{aligned}
$$

From the maximum and minimum values, $x_{5}(t)$ and $x_{6}(t)$ can be represented by

$$
\begin{aligned}
& x_{5}(t)=N_{a}\left(x_{5}(t)\right) \times 0.2+N_{b}\left(x_{5}(t)\right) \times(-0.2) \\
& x_{6}(t)=N_{c}\left(x_{6}(t)\right) \times 0.2+N_{d}\left(x_{6}(t)\right) \times(-0.2)
\end{aligned}
$$

where

$$
\begin{aligned}
& N_{a}\left(x_{5}(t)\right)+N_{b}\left(x_{5}(t)\right)=1 \\
& N_{c}\left(x_{6}(t)\right)+N_{d}\left(x_{6}(t)\right)=1
\end{aligned}
$$

Therefore, the membership functions can be calculated as

$$
\begin{aligned}
& N_{a}\left(x_{5}(t)\right)=\frac{0.2+x_{5}(t)}{0.4}, N_{b}\left(x_{5}(t)\right)=\frac{0.2-x_{5}(t)}{0.4}, \\
& N_{c}\left(x_{6}(t)\right)=\frac{0.2+x_{6}(t)}{0.4}, N_{d}\left(x_{6}(t)\right)=\frac{0.2-x_{6}(t)}{0.4} .
\end{aligned}
$$

Then, the $T-S$ type fuzzy model forms of AUV systems are as follows:

$\begin{aligned} \text { Rule": } & \text { IF } x_{5}(t) \text { is " } N_{a} \text { " and } x_{6}(t) \text { is " } N_{c} \text { " } \\ & \text { THEN } \dot{x}(t)=\boldsymbol{A}_{1} x(t)+\boldsymbol{B}_{1} u(t)\end{aligned}$

Rule 2 IF $x_{5}(t)$ is " $N_{a}$ " and $x_{6}(t)$ is " $N_{d}$ " THEN $\dot{x}(t)=\boldsymbol{A}_{2} x(t)+\boldsymbol{B}_{2} u(t)$

Rule $^{3}:$ IF $x_{5}(t)$ is " $N_{b}$ " and $x_{6}(t)$ is " $N_{c}$ " THEN $\dot{x}(t)=\boldsymbol{A}_{3} x(t)+\boldsymbol{B}_{3} u(t)$

Rule 4 IF $x_{5}(t)$ is " $N_{b}$ " and $x_{6}(t)$ is " $N_{d}$ " THEN $\dot{x}(t)=\boldsymbol{A}_{4} x(t)+\boldsymbol{B}_{4} u(t)$

where

$\boldsymbol{A}_{1}=\left[\begin{array}{cccccc}0 & -0.2000 & 0 & 1 & 0 & 0 \\ -0.2000 & 0 & 0 & 0 & 1 & 0 \\ 0 & 0 & 0 & 0 & 0 & 1 \\ 0 & 0 & 0 & -0.3256 & 0.2465 & 0 \\ 0 & 0 & 0 & -0.1623 & -0.3774 & 0 \\ 0 & 0 & 0 & -0.0377 & 0 & -0.3774\end{array}\right]$

$\boldsymbol{A}_{2}=\left[\begin{array}{cccccc}0 & -0.2000 & 0 & 1 & 0 & 0 \\ 0.2000 & 0 & 0 & 0 & 1 & 0 \\ 0 & 0 & 0 & 0 & 0 & 1 \\ 0 & 0 & 0 & -0.3256 & -0.2465 & 0 \\ 0 & 0 & 0 & 0.1623 & -0.3774 & 0 \\ 0 & 0 & 0 & -0.0377 & 0 & -0.3774\end{array}\right]$

$\boldsymbol{A}_{3}=\left[\begin{array}{cccccc}0 & 0.2000 & 0 & 1 & 0 & 0 \\ -0.2000 & 0 & 0 & 0 & 1 & 0 \\ 0 & 0 & 0 & 0 & 0 & 1 \\ 0 & 0 & 0 & -0.3256 & 0.2465 & 0 \\ 0 & 0 & 0 & -0.1623 & -0.3774 & 0 \\ 0 & 0 & 0 & 0.0377 & 0 & -0.3774\end{array}\right]$

$\boldsymbol{A}_{4}=\left[\begin{array}{cccccc}0 & -0.2000 & 0 & 1 & 0 & 0 \\ 0.2000 & 0 & 0 & 0 & 1 & 0 \\ 0 & 0 & 0 & 0 & 0 & 1 \\ 0 & 0 & 0 & -0.3256 & -0.2465 & 0 \\ 0 & 0 & 0 & 0.1623 & -0.3774 & 0 \\ 0 & 0 & 0 & 0.0377 & 0 & -0.3774\end{array}\right]$ 


$$
\boldsymbol{B}_{1}=\boldsymbol{B}_{2}=\boldsymbol{B}_{3}=\boldsymbol{B}_{4}=\left[\begin{array}{cc}
0 & 0 \\
0 & 0 \\
0 & 0 \\
0.0047 & 0 \\
0 & 0 \\
0 & 0.0038
\end{array}\right]
$$

The membership functions of this $T-S$ type fuzzy AUV system are shown in Fig. 5 and Fig. 6. The defuzzification is carried out as

$$
\dot{x}(t)=\sum_{i=1}^{4} h_{i}(x(t))\left\{\boldsymbol{A}_{i} x(t)+\boldsymbol{B}_{i} u(t)\right\}
$$

where

$$
\begin{aligned}
& h_{1}(x(t))=N_{a}\left(x_{5}(t)\right) \times N_{c}\left(x_{6}(t)\right) \\
& h_{2}(x(t))=N_{a}\left(x_{5}(t)\right) \times N_{d}\left(x_{6}(t)\right) \\
& h_{3}(x(t))=N_{b}\left(x_{5}(t)\right) \times N_{c}\left(x_{6}(t)\right) \\
& h_{4}(x(t))=N_{b}\left(x_{5}(t)\right) \times N_{d}\left(x_{6}(t)\right)
\end{aligned}
$$

This fuzzy model exactly represents the nonlinear system in the region $[-0.2,0.2] \times[-0.2,0.2]$ on the $x_{5}-$ $x_{6}$ space.

\section{FUZZY CONTROLLER DESIGN FOR NONLINEAR AUV SYSTEMS}

In the above section, the nonlinear AUV system has been transformed into the $T-S$ fuzzy model. To carry on, one can apply the fuzzy controller of the $T-S$ type fuzzy model for the AUV system. From the concept of PDC, we only need to design the linear controller for each rule, and then the controller of nonlinear system can be blended by the linear controllers of all rules. Applying the PDC concept, the fuzzy controller formula can be represented as follows:

$$
\begin{aligned}
& \text { Rule } 1 \text { IF } x_{5}(t) \text { is " } N_{a} \text { " and } x_{6}(t) \text { is " } N_{c} " \\
& \text { THEN } u(t)=\boldsymbol{F}_{1} x(t)
\end{aligned}
$$

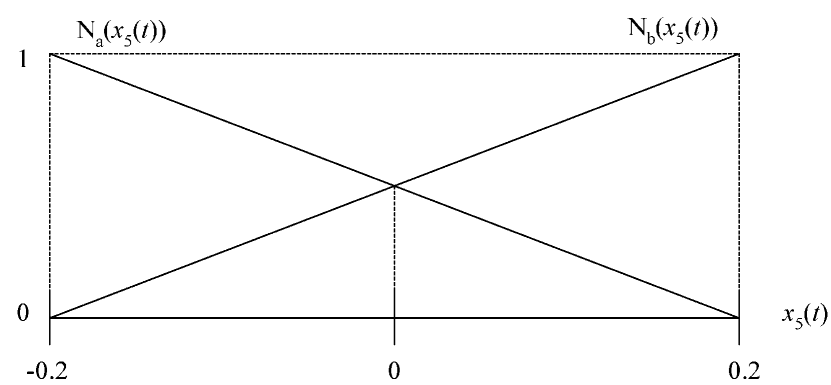

Fig. 5. Membership functions of $x_{5}(t)$.

$$
\begin{aligned}
& \text { Rule } 2 \text { IF } x_{5}(t) \text { is " } N_{a} \text { " and } x_{6}(t) \text { is " } N_{d} \text { " } \\
& \text { THEN } u(t)=\boldsymbol{F}_{2} x(t) \\
& \text { Rule : IF } x_{5}(t) \text { is " } N_{b} \text { " and } x_{6}(t) \text { is " } N_{c} \text { " } \\
& \text { THEN } u(t)=\boldsymbol{F}_{3} x(t) \\
& \text { Rule }{ }^{4}: \text { IF } x_{5}(t) \text { is " } N_{b} \text { " and } x_{6}(t) \text { is " } N_{d} \text { " } \\
& \text { THEN } u(t)=\boldsymbol{F}_{4} x(t)
\end{aligned}
$$

where $\boldsymbol{F}_{1}, \boldsymbol{F}_{2}, \boldsymbol{F}_{3}$ and $\boldsymbol{F}_{4}$ are the feedback gains for the AUV $T-S$ fuzzy controller design. Here, the output of the fuzzy controller is

$$
u(t)=\frac{\sum_{j=1}^{4} \omega_{j}(t)\left\{\boldsymbol{F}_{j} x(t)\right\}}{\sum_{j=1}^{4} \omega_{j}(t)}
$$

Substituting (48) into the AUV $T-S$ fuzzy model, one can obtain the closed-loop state equation as follows. The stability analysis is mentioned in [13, 15-17] for the closed-loop $T-S$ type fuzzy model. The closed-loop system is driven by the PDC-type fuzzy controller.

$$
\dot{x}(t)=\frac{\sum_{i=1}^{4} \sum_{j=1}^{4} \omega_{i}(t) \omega_{j}(t)\left\{\left(\boldsymbol{A}_{i}+\boldsymbol{B}_{i} \boldsymbol{F}_{j}\right) x(t)\right\}}{\sum_{i=1}^{4} \sum_{j=1}^{4} \omega_{i}(t) \omega_{j}(t)}
$$

Rewriting equation (49), one obtain

$$
\begin{aligned}
\dot{x}(t) & =\frac{1}{W}\left\{\sum_{i=1}^{4} \omega_{i}(t) \omega_{i}(t)\left(\boldsymbol{A}_{i}+\boldsymbol{B}_{i} \boldsymbol{F}_{i}\right) x(t)\right\} \\
& +\frac{1}{W}\left\{2 \sum_{i<j} \omega_{i}(t) \omega_{j}(t) \boldsymbol{R}_{i j} x(t)\right\}
\end{aligned}
$$

where

$$
W=\sum_{i=1}^{4} \sum_{j=1}^{4} \omega_{i}(t) \omega_{j}(t)
$$

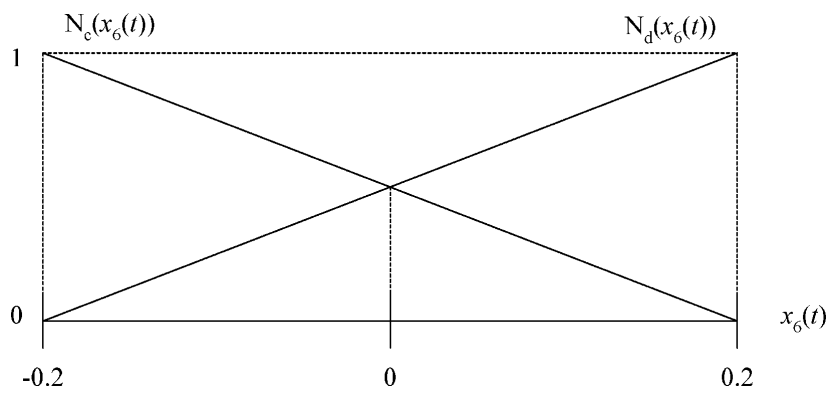

Fig. 6. Membership functions of $x_{6}(t)$. 


$$
\boldsymbol{R}_{i j}=\frac{\left(\boldsymbol{A}_{i}+\boldsymbol{B}_{i} \boldsymbol{F}_{j}\right)+\left(\boldsymbol{A}_{j}+\boldsymbol{B}_{j} \boldsymbol{F}_{i}\right)}{2}, i<j
$$

and $W$ is the total weight; $\boldsymbol{R}_{i j}$ represents the influence item between each other rules.

\section{Theorem 1 [14]}

If there exists a common matrix $\boldsymbol{P}$ satisfying the following two conditions (53) and (54), then the AUV $T$ $-S$ fuzzy model is asymptotically stable in the large.

$$
\left(\boldsymbol{A}_{i}+\boldsymbol{B}_{i} \boldsymbol{F}_{i}\right)^{T} \boldsymbol{P}+\boldsymbol{P}\left(\boldsymbol{A}_{i}+\boldsymbol{B}_{i} \boldsymbol{F}_{i}\right)<0, i=1,2,3,4
$$

$$
\boldsymbol{R}_{i j}^{T} \boldsymbol{P}+\boldsymbol{P} \boldsymbol{R}_{i j}<0, i<j
$$

The stability analysis of $T-S$ type fuzzy system depends on the common positive definite matrix $\boldsymbol{P}$ and linear feedback gains $\boldsymbol{F}_{i}$. Most of procedures are developed to find the suitable $\boldsymbol{P}$ and $\boldsymbol{F}_{i}$ to satisfy (53) and (54) by iterative methods. Here, one will use the LMI methodology to deal with the present problem. It is assumed that there is an LMI of the following form:

$$
\boldsymbol{G}(\kappa)=\boldsymbol{G}_{0}+\sum_{i=1}^{m} \kappa_{i} \boldsymbol{G}_{i}>0
$$

where $\kappa^{T}=\left[\begin{array}{llll}\kappa_{1} & \kappa_{2} & \ldots & \kappa_{m}\end{array}\right]$ is the variable and the symmetric matrices $\boldsymbol{G}_{i}=\boldsymbol{G}_{i}^{\boldsymbol{T}} \in \boldsymbol{R}^{n \times n}, i=0, \ldots, m$ are given. The inequality symbol $>0$ means that $\boldsymbol{G}(\kappa)$ is positive definite. Considering (55), the purpose of LMI methodology is to find $k$ such that $\boldsymbol{G}(\kappa)>0$.

The LMI (55) is a convex constraint on $\kappa$, i.e., the set $\{\kappa \mid \boldsymbol{G}(\kappa)>0\}$ is convex. In the control theory, many stability conditions can be transformed into an LMI form, such as Lyapunov inequality. The Lyapunov inequality for continuous-time system has the following form:

$$
\boldsymbol{A}^{T} \boldsymbol{P}+\boldsymbol{P A}<0
$$

In this paper, the stability conditions (53) and (54) can be transformed into an LMI if one assign $\boldsymbol{F}_{i}=\boldsymbol{K}_{i} \boldsymbol{P}^{-}$ 1. Applying the interior point polynomial method [9, 10], one can find the solutions of LMI by the LMItoolbox of MATLAB software. It can easily find the common positive definite matrix $\boldsymbol{P}$ and linear feedback controllers $\boldsymbol{F}_{i}$ for each rule for satisfying the sufficient stability conditions (53) and (54).

Now, the numerical simulations will be given to show the application of the present approach for the AUV nonlinear systems. Applying LMI-toolbox of MATLAB, one can find a suitable common positive definite matrix $\boldsymbol{P}$ and linear feedback controllers $\boldsymbol{F}_{i}, i=$ $1,2,3,4$, to satisfy (53) and (54). The solutions can be found as follows:
$\boldsymbol{P}=10^{-3} \times\left[\begin{array}{cccccc}10.3642 & -0.0000 & -0.0000 & 23.4319 & 1.3525 & -0.0000 \\ -0.0000 & 9.4862 & -0.0000 & 0.0000 & 25.1384 & -0.0000 \\ -0.0000 & -0.0000 & 12.4312 & 0.0000 & 0.0000 & 30.2953 \\ 23.4319 & 0.0000 & 0.0000 & 81.0392 & 36.0950 & -0.0000 \\ 1.3525 & 25.1384 & 0.0000 & 36.0950 & 155.8894 & 0.0000 \\ -0.0000 & -0.0000 & 30.2953 & -0.0000 & 0.0000 & 92.2957\end{array}\right]$

$\boldsymbol{F}_{1}=\left[\begin{array}{cccccc}-6.4366 & -1.6113 & 0.8638 & -22.5729 & -16.9749 & 2.5591 \\ 0.5367 & 0.0000 & -6.3381 & 1.6883 & 0.5001 & -18.7734\end{array}\right]$

$\boldsymbol{F}_{2}=\left[\begin{array}{cccccc}-7.4347 & 1.6113 & 1.3363 & -23.4170 & -1.7829 & 3.9590 \\ 0.7643 & -0.0000 & -6.4283 & 2.6511 & 1.2732 & -19.0404\end{array}\right]$

$\boldsymbol{F}_{3}=\left[\begin{array}{cccccc}-6.4366 & -1.6113 & -0.8638 & -22.5729 & -16.9749 & -2.5591 \\ -0.5367 & 0.0000 & -6.3381 & -1.6883 & -0.5001 & -18.7734\end{array}\right]$

$\boldsymbol{F}_{4}=\left[\begin{array}{cccccc}-7.5347 & 1.6113 & -1.3363 & -23.4170 & -1.7829 & -3.9590 \\ -0.7643 & -0.0000 & -6.4283 & -2.6511 & -1.2732 & -19.0404\end{array}\right]$

The above fuzzy controller satisfies the stability conditions (53) and (54). Hence, the $T-S$ type fuzzy model of AUV system is stable with the linear feedback gains given in (58) to (61).

\section{SIMULATIONS}

In this section, the simulation results will be presented for the AUV dynamic real model (10-18) and AUV dynamic $T-S$ fuzzy model (39), respectively. It is done by using the MATLAB fuzzy toolbox and SIMULINK toolbox. The system parameters of this simulation are given as follows: $m_{11}=215(\mathrm{~kg}), m_{22}=$ $265(\mathrm{~kg}), m_{33}=265(\mathrm{~kg}), d_{11}=70(\mathrm{~kg}), d_{22}=100(\mathrm{~kg})$ and $d_{33}=100(\mathrm{~kg})$. Moreover, the initial conditions of system states of this simulation are stated by $\left[x_{1}(0)\right.$, $\left.x_{2}(0), x_{3}(0), x_{4}(0), x_{5}(0), x_{6}(0)\right]^{T}=[20(\mathrm{~m}), 1(\mathrm{~m}), 1(\mathrm{rad})$, $0(\mathrm{~m} / \mathrm{s}), 0(\mathrm{~m} / \mathrm{s}), 0(\mathrm{rad} / \mathrm{s})]^{T}$. Fig. 7 and Fig. 8 are the simulation results of AUV dynamic real model and AUV dynamic $T-S$ fuzzy model without fuzzy control. In fuzzy control case, the desired trajectory is $\left[x_{1}, x_{2}\right]=$ $[0,10]$. Fig. 9 to Fig. 13 show the simulation results 
with fuzzy control input gains (58) to (61). From this simulation, one can find that the control errors are $\left[x_{1}\right.$, $\left.x_{2}\right]=[0.027,0.049]$ for real system; and [0.026, 0.022] for $T-S$ type fuzzy system.

Through the above simulation results, it can be found that AUV system can be transformed into $T-S$ type fuzzy model via the $T-S$ type fuzzy modeling method. Moreover, the control problem of AUV nonlinear dynamic system can be solved by the LMI-based fuzzy type control method. It is a practical approach for the control problem for nonlinear AUV systems.

\section{CONCLUSIONS}

In this paper, the idea of sector nonlinearity in fuzzy model has been used to implement a nonlinear dynamic AUV system. The sector nonlinearity is based on the idea of finding a global sector such that $\dot{x}(t)=f(x$

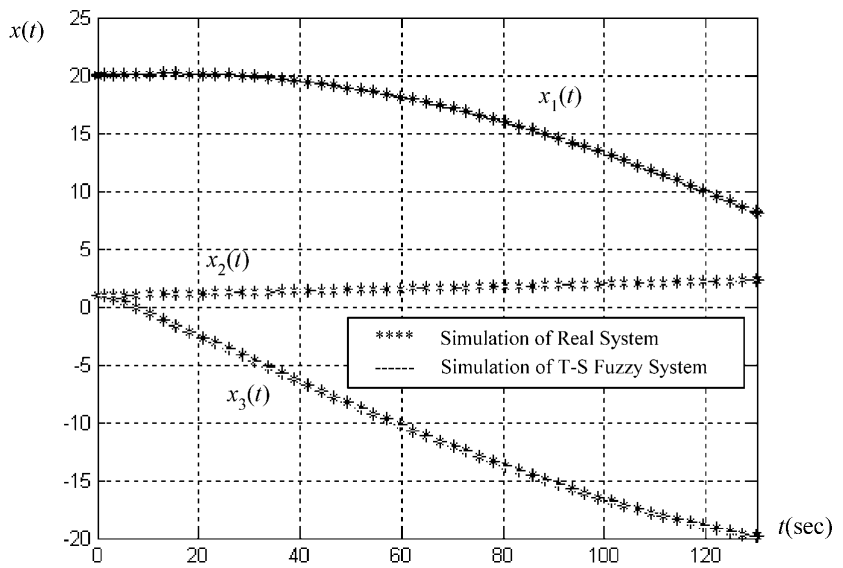

Fig. 7. The $x_{1}(t)-x_{3}(t)$ plot without fuzzy controller.

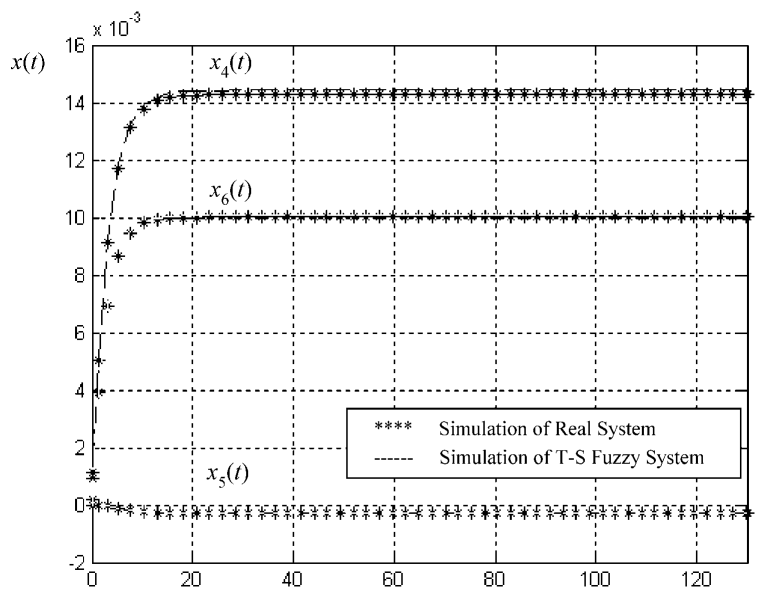

$t(\sec )$

Fig. 8. The $x_{4}(t)-x_{6}(t)$ plot without fuzzy controller. $(t)) \in\left[a_{1}, a_{1}\right] x(t)$. This approach guarantees an exact fuzzy model construction. Through the idea of sector nonlinearity and $T-S$ type fuzzy modeling method, one can construct the $T-S$ type fuzzy model of nonlinear dynamic AUV system. Through the PDC concept, the linear controller design method allows us to design the feedback gain in each rule. Then, the fuzzy controller of nonlinear system can be blended by the linear controllers of all rules. Applying the LMI design methodology, one can solve linear feedback gain for each rule to satisfy the stability conditions for the $T-S$ type fuzzy AUV systems.

\section{ACKNOWLEDGEMENT}

This work was supported by the National Science Council of the Republic of China under Contract NSC912815-C-019-002-E.

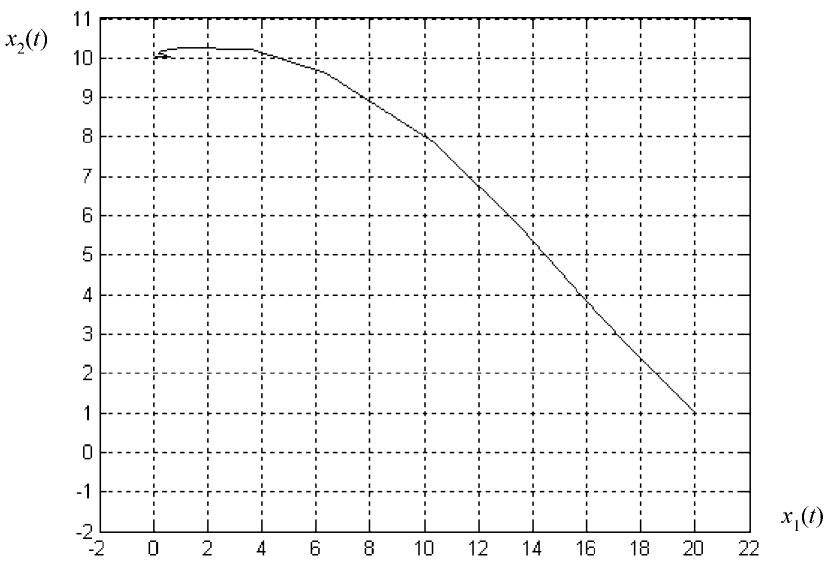

Fig. 9. The $x_{1}(t)-x_{2}(t)$ plot.

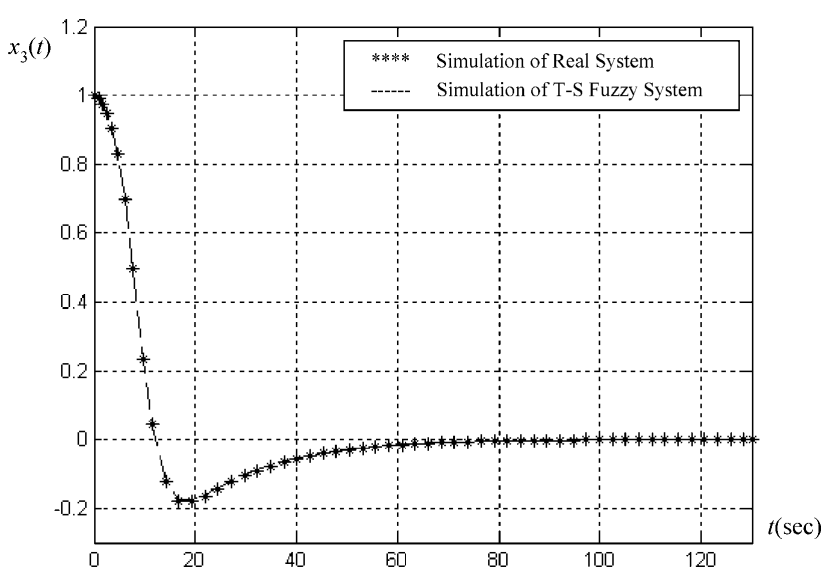

Fig. 10. The transitional coordinate of $x_{3}(t)$. 


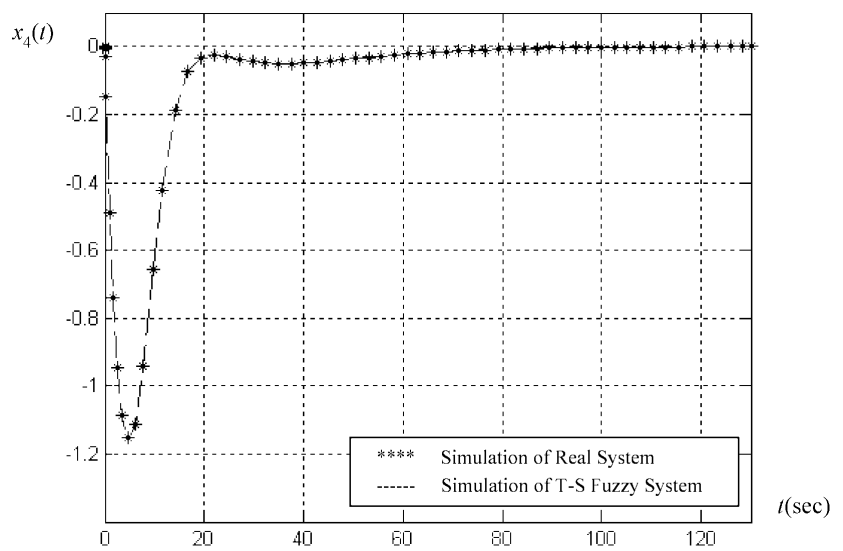

Fig. 11. The surge speed $x_{4}(t)$.

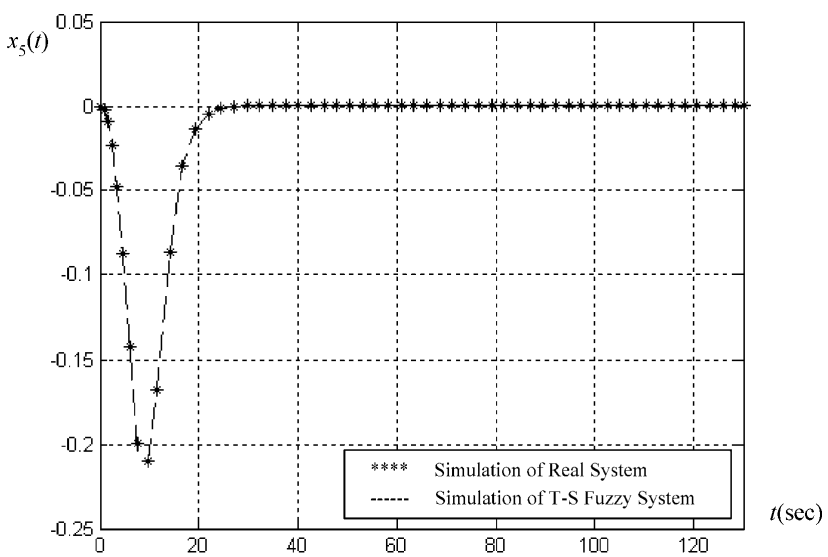

Fig. 12. The sway speed $x_{5}(t)$.

\section{REFERENCES}

1. Aguiar, A.P. and Pascoal, A.M., "Regulation of a Nonholonomic Autonomous Underwater Vehicle with Parametric Modeling Uncertainty Using Lyapunov Functions," Proc. 40th IEEE Conf. Decision Control, Vol. 5, pp. 4178 -4183 (2001).

2. Chang, W.J., "Model-Based Fuzzy Controller Design with Common Observability Gramian Assignment," ASME, J. Dynamic Syst., Measure. Control, Vol. 123, No. 1, pp. 113-116 (2001).

3. Chang, W.J., "Fuzzy Controller Design via the Inverse Solution of Lyapunov Equations," ASME, J. Dynamic Syst., Measure. Control, Vol. 125, No. 1, pp. 42-47 (2003).

4. Chang, W.J. and Chang, K.Y., "Multivariable Performance-Constrained Sliding Mode Control for Ship YawMotion Systems with Perturbations," Int. J. Adaptive Control Signal Proce., Vol. 14, No. 4, pp. 393-409 (2000).

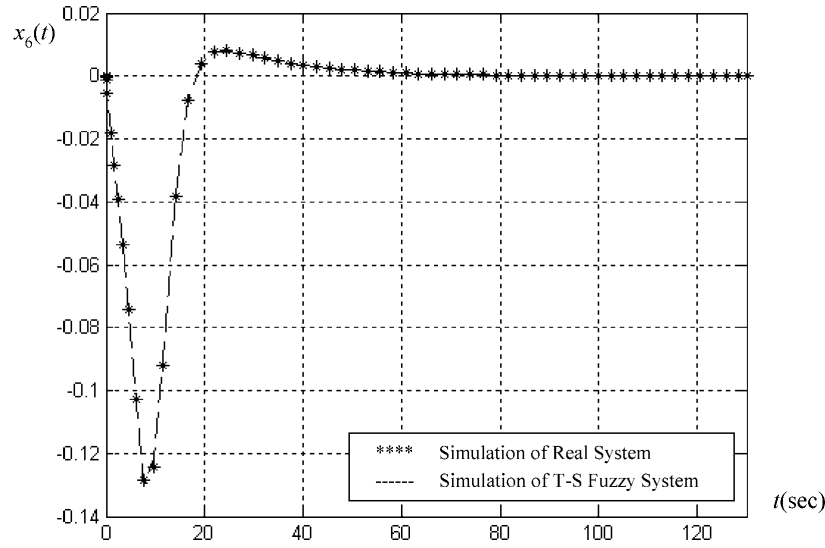

Fig. 13. The vehicle's angular speed $x_{6}(t)$.

5. Chang, W.J. and Sun, C.C., "Constrained Fuzzy Controller Design of Discrete Takagi-Sugeno Fuzzy Models," Fuzzy Sets Syst., Vol. 133, No. 1, pp. 37-55 (2003).

6. Chang, W.J. and Yeh, Y.L., "LMI-Based T-S Fuzzy Controller Design for Ship Steering System," J. Soc. Naval Arch. Mar. Engs., Vol. 21, No. 4, pp. 209-217 (2002).

7. Chang, W.J., Chen, G.J., and Yeh, Y.L., "Fuzzy Control of Dynamic Positioning Systems for Ships," J. Marine Sci. Technol., Vol. 10, No. 1, pp. 47-53 (2002).

8. Fossen, T.I., Guidance and Control of Ocean Vehicles, John Wiley and Sons, New York (1994).

9. Hertog, D.den., Interior Point Approach to Linear, Quadratic, and Convex Programming: Algorithms and Complexity, Kluwer Academic, New York (1994).

10. Nesterov, Y. and Nemirovski, A., Interior Point Algorithms in Convex Programming: Theory and Application, SIAM Books, Philadelphia (1994).

11. Pettersen, K.Y. and Egeland, O., "Robust Control of an Underactuated Surface Vessel with Thruster Dynamics," Proc. American Control Conf., Vol. 5, pp. 3411 -3415 (1997).

12. Takagi, T. and Sugeno, M., "Fuzzy Identification of Systems and Its Applications to Modeling and Control," IEEE Trans. Syst., Man Cybernetics, 15(1): 116132 (1985).

13. Tanaka, K. and Wang, H.O., Fuzzy Control System Design and Analysis-A Linear Matrix Inequality Approach, John Wiley and Sons, New York (2001).

14. Tanaka, K., Ikeda, T., and Wang, H.O., "Fuzzy Control System Design via LMIs," Proc. American Control Conf., New Mexico, pp. 2873-2877 (1997).

15. Wang, H.O. and Tanaka, K., "An LMI-based Stable Fuzzy Control of Nonlinear Systems and Its Application to Control of Chaos," Proc. 5th Int. Fuzzy Syst. Conf., pp. 1433-1438 (1996). 
16. Wang, H.O., Tanaka, K., and Griffin, M., "Parallel Distributed Compensation of Nonlinear Systems by Takagi-Sugeno Fuzzy Model," Proc. 1995 IEEE Int. Conf. Fuzzy Syst., pp. 531-538 (1995).

17. Wang, H.O., Tanaka, K., and Griffin, M., “An Approach to Fuzzy Control of Nonlinear Systems: Stability and
Design Issues," IEEE Trans. Control Syst., Vol. 4, No. 1, pp. 14-23 (1996).

18. Wu, S.M., Chang, W.J., and Yeh, Y.L., "Fuzzy Modeling and Control for Dynamic Positioning Systems of Ships," Proc. 4th Asian Control Conf., pp. 209-214, Singapore (2002). 